\title{
Predicting mussel population density and age structure: the relationship between model complexity and predictive power
}

\author{
R. A. Stillman*, S. McGrorty, J. D. Goss-Custard, A. D. West \\ Centre for Ecology and Hydrology Dorset, Winfrith Technology Centre, Winfrith Newburgh, Dorchester, Dorset DT2 8ZD, \\ United Kingdom
}

\begin{abstract}
We use a model to predict the age structure and density of an intertidal mussel Mytilus edulis L. population on the 10 primary mussel beds of the Exe estuary, England. We investigate the relationship between the number of parameters in the model and its accuracy in describing the observed density-age structure. The full detail version (382 parameters) assumes that recruitment rates are bed-specific and mortality rates are age-class, bed- and season-specific, and describes the observed age structure and density very accurately; the predicted estuary-wide density in March is $581 \mathrm{~m}^{-2}$ compared with an observed density of $578 \mathrm{~m}^{-2}$ during 1977 to 1983 . The simplest version (24 parameters) describes the age structure and density almost as well (predicted estuary-wide density of $568 \mathrm{~m}^{-2}$ ) and assumes that: (1) density-dependence is absent in the 3rd-winter and older mussels, and density-independent mortality in these age classes is the same on all beds, but increases with age $_{i}(2)$ in younger mussels, density-dependent mortality operates above a threshold mussel density which is determined by bed exposure and has a strength which is the same on all beds, but which varies with age class; (3) recruitment rate is dependent on the density of adults on a bed and the bed's substrate softness. The model is tested by comparing its predictions, based on data collected during 1976 to 1983, with observed mussel densities during 1992 to 1997; a stable September mussel population of 524 adults $\mathrm{m}^{-2}$ is predicted and, in accord with this, the observed density of adults in September changed relatively little between 1976 and $1983\left(541 \mathrm{~m}^{-2}\right)$ and between 1992 and 1997 $\left(450 \mathrm{~m}^{-2}\right)$. We discuss why the number of parameters in the model can be reduced so greatly with very little reduction in the accuracy of predictions, and whether a similar approach could be used to model other shellfish populations.
\end{abstract}

KEY WORDS: Density-dependence $\cdot$ Estuarine $\cdot$ Inter-tidal $\cdot$ Population dynamics $\cdot$ Recruitment

\section{INTRODUCTION}

A long-term study of the mussel Mytilus edulis L. population of the Exe estuary has identified a high degree of variation in recruitment and mortality rates among different mussel beds located along environmental gradients throughout the estuary, and strong population regulation occurring mainly through density-dependent recruitment and mortality in young age classes (McGrorty et al. 1990, 1993, McGrorty \& GossCustard 1991, 1993, 1995). In this paper we develop an

*E-mail: rast@ceh.ac.uk age-structured model of this population based on the data collected during the study. The purpose of this model is to predict, as accurately as possible, the density of mussel age classes, on each of 10 mussel beds, at the beginning and end of winter. The study was carried out at a fine bed-scale in order to better understand the functioning of the mussel system at the larger estuarine scale and because the model's output is used as input to a separate model of an oystercatcher Haematopus ostralegus L. population, whose primary food is mussels (Stillman et al. 2000). Because of the length and intensity of the field study, enough data are available for us to initially build a highly detailed model in which, for example, density-dependent mortality 
rates vary among mussel beds, mussel age classes and between seasons. However, this detailed model is too Exe-estuary-specific to be applied to another system, and of little general value. We therefore show how the accuracy with which the model describes the real system changes as it is made more and more simple; for example, by assuming that mortality rates are the same on different mussel beds or by using environmental characteristics of beds to predict mortality rates rather than measuring rates separately on each bed. We find that the model can be simplified considerably with very little loss of its descriptive power. We discuss reasons for this and whether similar simplification will be possible in models of other shellfish populations.

\section{METHODS}

Study area. The Exe estuary is sheltered, and so its mussel Mytilus edulis L. population does not suffer from the catastrophic mortalities due to storms and other disturbance sources which dominate populations on rocky shores and in large embayments (e.g. Dare 1976). The majority of the Exe mussel beds were originally laid by man, probably over 100 yr ago, when extensive shellfishing occurred throughout the estuary. With the possible exceptions of Beds 30 and 31, which lie on a gravel substrate close to the estuary mouth and are probably natural, most beds were laid in discrete patches on muddy or sandy substrates. Beds were tended and restocked by man until the 1940s, but after this time persisted naturally. More spat settle on Beds 30 and 31 near the estuary mouth than on up-estuary beds, but density-dependent mortality greatly reduces the variation in the numbers of surviving adults among beds. The proportions of spat originating from within and outside of the estuary are unknown. The formation of a new mussel bed on the Exe is an extremely rare event, having been observed only once in $25 \mathrm{yr}$, when spat survived for 2 to 3 yr after they settled on a patch of tube worms Lanice conchilega (Pallas) (S.M. pers. obs.). Almost all the mussels in the estuary occur on 10 mussel beds which, with 4 exceptions, are spatially distinct, being separated by areas of bare mud. The exceptions are Beds 3 and 4, which are separated by a stream, and Beds 30 and 31, which are separated by a gully. The mussel beds are spread widely throughout the estuary, 0.8 to $3.0 \mathrm{~km}$ from the estuary mouth, but with most lying in a line up the eastern side of the estuary. They vary widely in their duration of exposure and substrate softness (muddiness), with those furthest from the estuary mouth having the lowest exposure and softest substrate. Previous studies have shown that these environment gradients cause variation in the dynamics of the mussel population among the different beds. Further details and a map of the Exe estuary and its mussel population can be found in McGrorty et al. (1990). The area, exposure, distance from the estuary mouth, and substrate softness of each bed are listed in Table 1 of McGrorty \& Goss-Custard (1991).

Field methods. The field data were collected between September 1976 and September 1983 from the 10 primary mussel beds $(1,3,4,20,22,25,26,27$, 30 and 31 ). The methods used to collect these data have been described in detail elsewhere (McGrorty et al. 1990, McGrorty \& Goss-Custard 1995) and so are only described briefly here. Each bed was surveyed in September and March each year, using a stratified random sample of $20 \times 20 \mathrm{~cm}$ quadrats, to record the density of mussels in each of 9 age (year) classes. Mussel spat settlement peaks on the Exe in late winter/spring, and although it continues throughout summer (McGrorty et al. 1990), regardless of their actual age, spat were assumed to be $1 \mathrm{yr}$ old the following March, and older mussels were also assumed to age in March.

Data analysis. The model was parameterized using data collected during 1976 to 1983. Linear regression equations were developed to predict age-class mortality rates (henceforth referred to as 'mortality') during the winter (September to March) and summer (March to September), and the density of new recruits in September (henceforth referred to as 'recruitment'). For consistency with previous studies (e.g. McGrorty \& Goss-Custard 1995), mortality was expressed as $k$-values. On the Exe, both mortality, particularly of 1st-winter mussels, and September recruitment are densitydependent (McGrorty et al. 1990, McGrorty \& GossCustard 1995), and so mussel density was used as an explanatory variable in the equations. Equations of age-class mortality used the density of the age class itself at the start of the season ( $\log _{10}$ transformed), and those of the density of new recruits used the September density of all older age classes (also $\log _{10}$ transformed). Trials showed that mortality and recruitment were less strongly related to other measures of mussel density. The weather may also influence mussel mortality (McGrorty \& Goss-Custard 1995), and so both mortality and recruitment were regressed against mean seasonal temperature, total seasonal rainfall and the number of gale days (wind stronger than Force 4), as well as mussel density. However, none of these weather variables were consistently related to either mortality or recruitment, and so were not considered further. Therefore, the final set of equations used in the analysis contained only mussel density as an explanatory variable. A range of equations were developed, each making different assumptions about the variation in recruitment and mortality among age classes and beds. To avoid selectivity, all parameter estimates were used in the model regardless of whether they were sig- 
nificantly different from zero. During the model simplification process, regression equations were developed which related the mortality or recruitment on a bed to the proportion of the tidal cycle which the bed is exposed, the bed's substrate softness, and the distance between the bed and the mouth of the estuary (see McGrorty \& Goss-Custard 1991 for the methods used to measure these variables).

Mussel population model. The model is age-structured and divides the mussel population on each bed into 9 age (year) classes. Each age class is further divided into winter (September to March) and summer (March to September). The youngest age class modelled is 1st winter (represented by Age Class 1 in winter), followed by 2nd summer (Age Class 1 in summer), 2nd winter (Age Class 2 in winter) and 3rd summer (Age Class 2 in summer). The oldest age classes are 9th winter (Age Class 9 in winter) and 10th summer (Age Class 9 in summer). The model ignores 1st summer mussels because they settle throughout March to September and so their abundance fluctuates widely during this period. Simulations start in September and are initially seeded with the average density of each age class recorded on the bed between 1976 and 1983. In subsequent years, ageing and recruitment happen each September. The density $(D)$ of recruits each September is dependent on adult density:

$$
D_{1, j, 1}=a_{1, j, 1}+b_{1, j, 1} \log _{10}\left(\sum_{i=2}^{9} D_{i, j, 1}\right)
$$

where $i=$ age class number $(1-9), j=$ bed number (1-10), $D_{1, j, 1}=$ density of recruits on Bed $j$ in September, $a$ and $b=$ coefficients estimated by linear regression of recruit density against adult density, $D_{i, j, 1}=$ density of Age Class $i$ on Bed $j$, in September. In the full-detail model, the values of $a$ and $b$ are bed-specific. On the Exe, spat usually only survive when they settle amongst the byssus threads of adults, which provide a refuge from crab Carcinus maenas L. predation (McGrorty et al. 1993). Each adult mussel can only provide a refuge for a limited number of spat, and so to remove the possibility of predicting unrealistically high densities of recruits, the model limits the maximum number of recruits per adult:

$$
\begin{aligned}
D_{1, j, 1}= & a_{1, j, 1}+b_{1, j, 1} \log _{10}\left(\sum_{i=2}^{9} D_{i, j, 1}\right) \\
\text { if } \quad & a_{1, j, 1}+b_{1, j, 1} \log _{10}\left(\sum_{i=2}^{9} D_{i, j, 1}\right) \leq m \sum_{i=2}^{9} D_{i, j, 1} \\
D_{1, j, 1}= & m \sum_{i=2}^{9} D_{i, j, 1} \\
\text { if } \quad & a_{1, j, 1}+b_{1, j, 1} \log _{10}\left(\sum_{i=2}^{9} D_{i, j, 1}\right)>m \sum_{i=2}^{9} D_{i, j, 1}
\end{aligned}
$$

where $m=$ maximum number of recruits per adult; $m$ was set to 25, the maximum number of spat recorded on an adult mussel on the Exe (S.M. unpubl. data). This means that the maximum number of recruits per adult predicted by the model can never exceed that observed. The main consequence of this assumption is that, as in the real system, the density of adults on a bed will limit the density of recruits if adults become rare.

Mortality occurs during both the winter and summer, and is dependent on age-class density:

$$
K_{i, j, \mathrm{k}}=C_{i, j, \mathrm{k}}+d_{i, j, \mathrm{k}} \log _{10}\left(D_{i, j, \mathrm{k}}\right)
$$

where $K_{i, j, k}=$ mortality ( $k$-value) of Age Class $i$, on Bed $j$ during season $k(1=$ winter; $2=$ summer $), c$ and $d=$ coefficients estimated by linear regression of $k$-value against age-class density, and $D_{i, j, k}=$ density of Age Class $i$, on Bed $j$ during season $k$. In the full-detail model the values of $c$ and $d$ are age-class-, bed- and season-specific. The immigration of adult mussels from sub-littoral areas to mussel beds occurs on the Exe (McGrorty \& Goss-Custard 1995), causing negative $k$ values. To prevent unrealistically high levels of immigration, the minimum $k$-value generated by the model was limited:

$$
\begin{aligned}
K_{i, j, \mathrm{k}}= & c_{i, j, \mathrm{k}}+d_{i, j, \mathrm{k}} \log _{10}\left(D_{i, j, \mathrm{k}}\right) \\
\text { if } \quad & C_{i, j, \mathrm{k}}+d_{i, j, \mathrm{k}} \log _{10}\left(D_{i, j, \mathrm{k}}\right) \geq K_{\min } \\
K_{i, j, \mathrm{k}}= & K_{\min } \\
\text { if } \quad & C_{i, j, \mathrm{k}}+d_{i, j, \mathrm{k}} \log _{10}\left(D_{i, j, \mathrm{k}}\right)<K_{\min }
\end{aligned}
$$

where $K_{\min }=$ minimum $k$-value. $K_{\min }$ was estimated by initially calculating the minimum $k$-value recorded on each bed, during the summer or winter, for Age Classes 1 to 5 (100 minimum $k$-values in total). We excluded the $k$-values of Age Classes 6 to 9 because the densities of these age classes were generally low and hence their $k$-values were subject to large errors. In order to represent the minimum $k$-value expected in any age class, during winter or summer, on any bed, $K_{\min }$ was calculated as the mean of these minimum $k$-values $(=-0.2)$.

Simulations were run over 100 yr. The Exe mussel population is highly regulated, with strong density-dependence in young age classes in particular (McGrorty et al. 1990), and so it was not surprising that the model predicted very stable mussel densities. Therefore, predictions were the average mussel density of each age class, on each bed, at the end of winter during the last $50 \mathrm{yr}$ of the simulation. There were no random components to the model and so only 1 simulation was run for each combination of parameter values.

Measuring model complexity and predictive power. We measured the complexity of the model as its num- 
ber of parameter values. For simplicity we did not distinguish between parameters that applied to all age classes, beds and seasons (e.g. the maximum number of recruits per adult $[\mathrm{m}]$ ) and those which applied only to a single age class, bed and season (e.g. the strength of density-dependent mortality of Age Class 1, on Bed 1 during the winter $\left.\left[d_{1,1,1}\right]\right)$.

Model predictions were compared with the observed March densities of the 9 age classes on the 10 beds in the $7 \mathrm{yr}$ from 1977 to 1983, giving a total of $630 \mathrm{com}$ parisons. The model's predictive power was measured as the percentage of the variation in the observed age class-, bed- and year-specific densities explained by its predicted age-class- and bed-specific densities $\left(R^{2}\right)$ (predictions were not year-specific as the model predicted the same density each year):

$$
\mathrm{R}^{2}=100 \times\left(1-\frac{\mathrm{RSS}}{\mathrm{SS}}\right)
$$

where RSS = residual sum of squares between predicted and observed densities and SS = sum of squares of observed densities. At each stage of model simplification we compared the fit of the simplified model with that of the full detail model using an $F$-ratio test (Bates \& Watt 1988):

$$
F=\frac{\left(\mathrm{RSS}_{\mathrm{s}}-\mathrm{RSS}_{\mathrm{f}}\right) /\left(p_{\mathrm{f}}-p_{\mathrm{s}}\right)}{\mathrm{RSS}_{\mathrm{f}} /\left(n-p_{\mathrm{f}}-1\right)}
$$

with $\left(p_{\mathrm{f}}-p_{\mathrm{s}}\right)$ and $\left(n-p_{\mathrm{f}}-1\right)$ degrees of freedom, where $\mathrm{RSS}_{\mathrm{s}}$ and $\mathrm{RSS}_{\mathrm{f}}=\mathrm{RSS}$ in the simplified and full detail model, respectively, $p_{\mathrm{s}}$ and $p_{\mathrm{f}}=$ number of parameters in the simplified and full detail models, respectively, and $n=$ sample size.

The simplification process was guided by the model's fit to the data used to parameterize it (i.e. 1976 to 1983). The comparisons made during this process were not a test of the model's predictive ability, but simply showed whether each successive model contained enough information to adequately describe the real system. However, the simplest version of the model was also compared with the mussel population densities in 1992, 1995 and 1997. No data from these years were used to parameterize the model and so this was a test of the model's predictive ability.

\section{RESULTS}

\section{Full-detail model}

The full-detail model assumed bed-specific relationships between recruit density in Mytilus edulis and adult density (Eq. 2; 2 parameters [ $a$ and $b$ ] on 10 beds $=20$ parameters) and age-class-, bed- and seasonspecific relationships between mortality and age class density (Eq. $4 ; 2$ parameters [ $c$ and $d$ ] for 9 age classes on 10 beds in 2 seasons $=360$ parameters). The model also assumed that the number of new recruits per adult mussel and the immigration rate were limited (parameters $m$ and $K_{\min }$ in Eqs. 2 \& 4, respectively). In total, the full-detail model contained 382 parameters (Fig. 1). The model's recruitment parameters varied considerably among beds (Fig. 2a,b), as did its mortality parameters among beds and age classes and between seasons (Fig. 2c,d).

Given that the model contained 382 parameters and was compared with the data used to estimate its para-

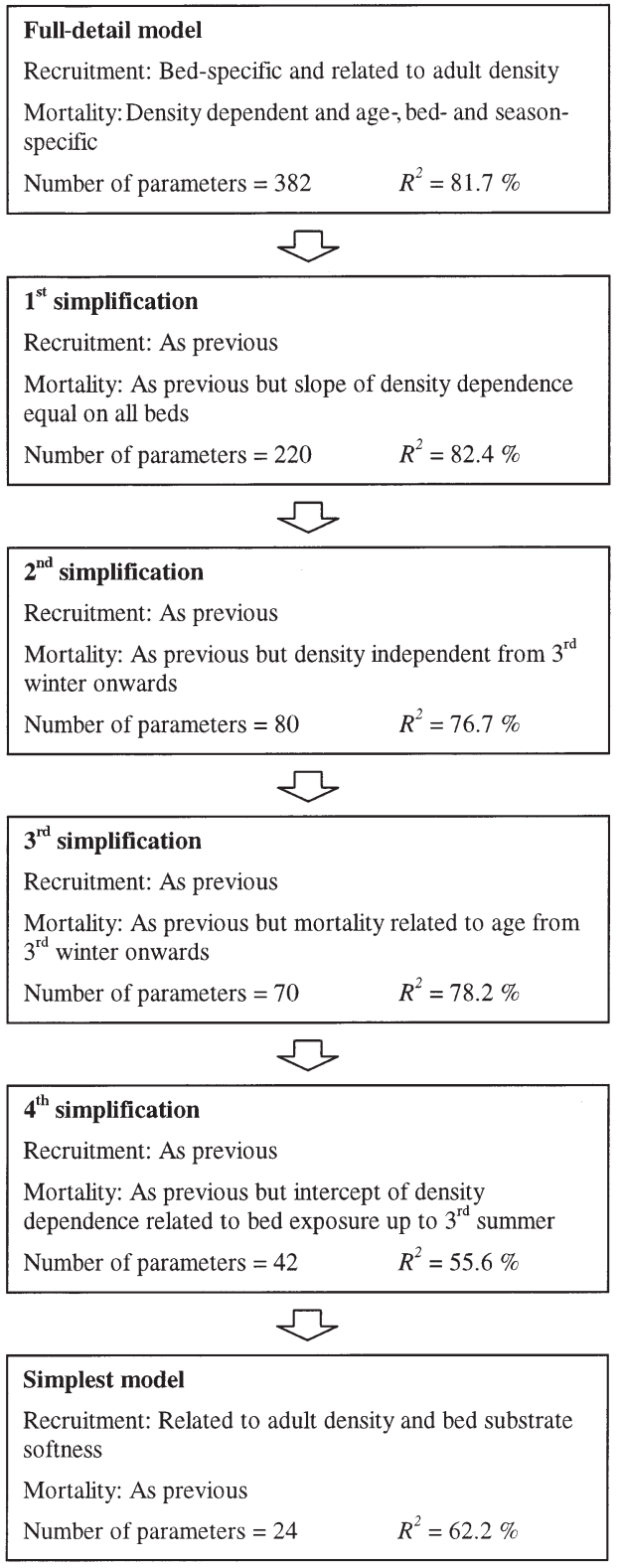

Fig. 1. Steps by which model was simplified 
meter values, it is not surprising that observed and predicted mussel densities were similar (Fig. 3). The model accurately predicted the density-age distribution of mussels on each bed and the variation in density among different beds. The predicted estuary-wide density of mussels in March was $581 \mathrm{~m}^{-2}$ compared with an observed density of $578 \mathrm{~m}^{-2}$. As the differences between observed and predicted were generally similar on all beds, all further comparisons are based on the estuary-wide densities of mussels. In both observed and predicted, the estuary-wide density of each age class was calculated as the average density across all beds.

\section{Simplifying the model}

The first stage of simplifying the model used the approach of McGrorty \& Goss-Custard (1995), who used 3 different regression models to describe the relationship between age-class density and mortality. These differed in whether the intercepts and slopes of this relationship were the same or differed among beds. In decreasing complexity, they assumed (1) bedspecific slopes $\left(d_{i, j, k}\right)$ and intercepts $\left(c_{i, j, k i}\right.$ Eq. 4$)$, (2) a common slope $\left(d_{i, k}\right)$ but bed-specific intercepts $\left(c_{i, j, k}\right)$ :

$$
K_{i, j, k}=C_{i, j, k}+d_{i, k} \log _{10}\left(D_{i, j, k}\right)
$$

or (3) a common slope $\left(d_{i, k}\right)$ and intercept $\left(C_{i, k}\right)$

$$
K_{i, j, k}=C_{i, k}+d_{i, k} \log _{10}\left(D_{i, j, k}\right)
$$

The first approach represents the full-detail 382parameter model, and as shown above this very accurately predicted density-age structure (Figs. 3 \& 4a). The simplified versions of the model were parameterized using regression models based on the assumptions in (2) and (3). The common slope, bed-specific intercept model had 220 parameters (180 age-class-, bed- and season-specific slopes, replaced by 18 ageclass- and season-specific ones) and a closer fit to the observed data than the full model, even though it contained just over half as many parameters (Fig. 4b) ( $F$-ratio test against full-detail model: $F<0.0$; df $=162$, 247; not significant, ns). It predicted a March estuarywide mussel density of $583 \mathrm{~m}^{-2}$. The common slope and (a) Recruitment intercepts

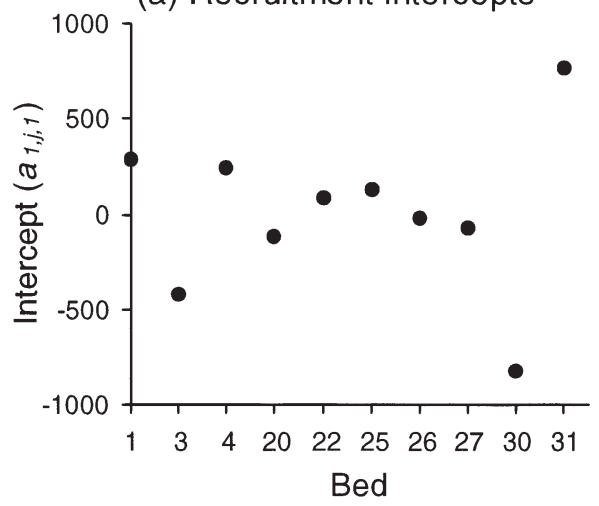

(c) Mortality intercepts

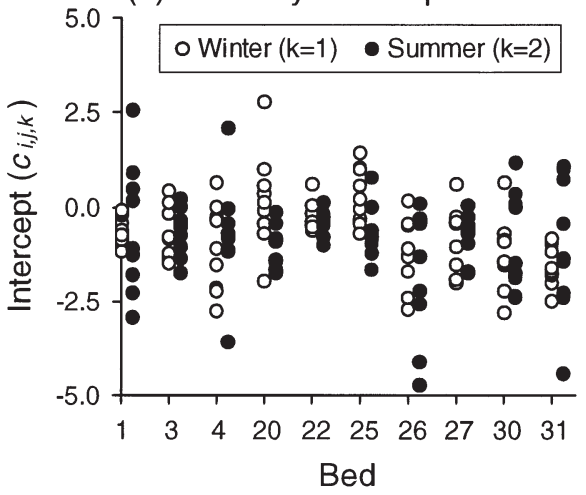

(b) Recruitment slopes

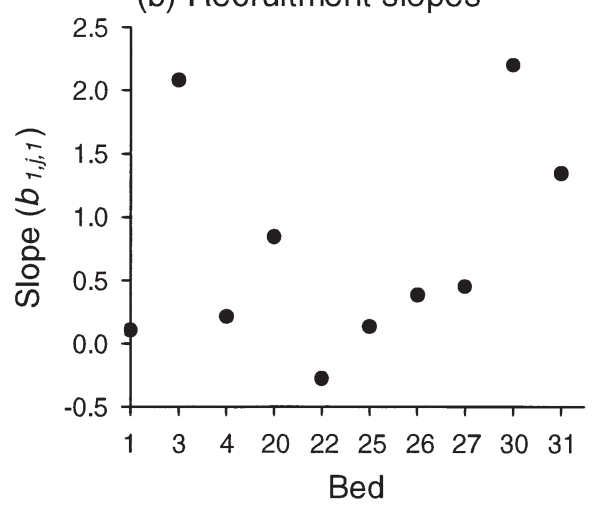

(d) Mortality slopes

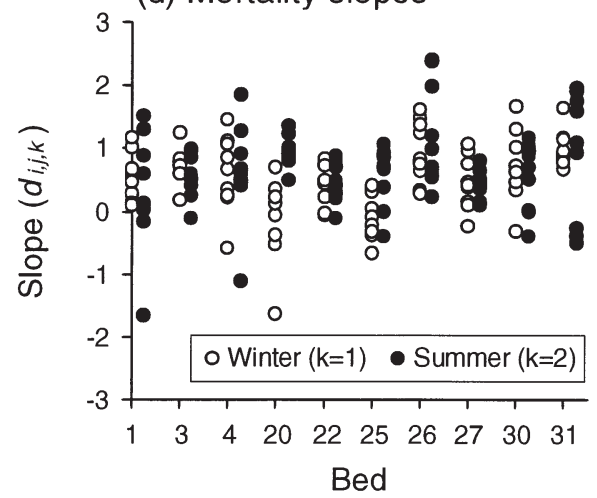

Fig. 2. Bed-specific recruitment $(\mathrm{a}, \mathrm{b})$ and mortality-parameter values $(\mathrm{c}, \mathrm{d})$ of the full-detail model. Each symbol in (c) and $(\mathrm{d})$ is the parameter value of 1 age class during either winter or summer. Data include 380 of the model's 382 parameters; the values of the 2 remaining parameters, $m$ and $K_{\min }$, are given in the text 

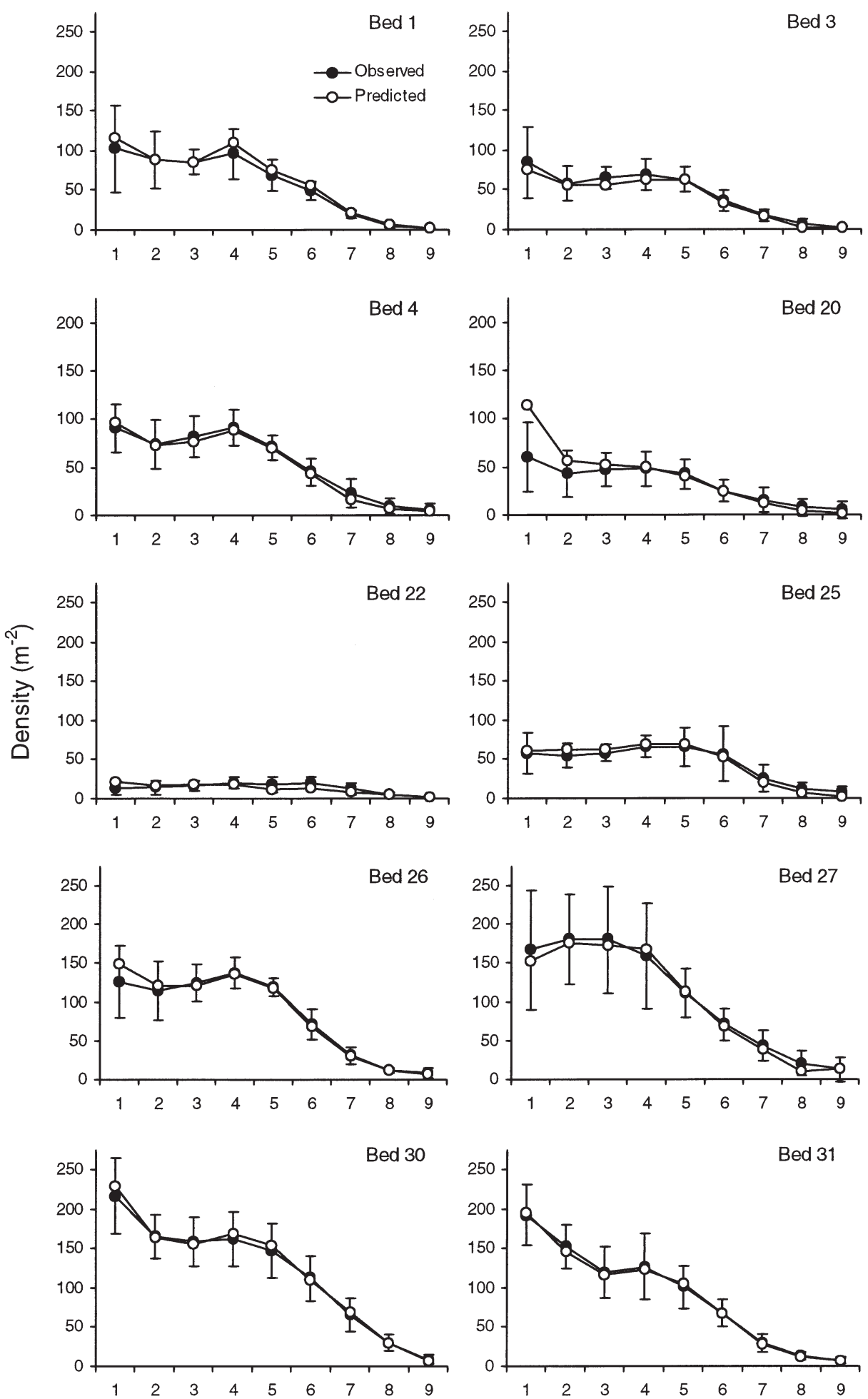

Age class

Fig. 3. Mytilus edulis. Predicted and observed bed-specific age distributions in March. Predictions calculated from full-detail model = mean age-class density during 50 yr. Observations are means and between-year standard deviations of age-class density during 1977 to 1983 (see 'Methods' for age-class definitions) 
intercept model had only 58 parameters (360 age-class-, bed- and season-specific slopes and intercepts, replaced by 36 age class- and season-specific ones), but had a poor fit to the data (Fig. 4c) (F-ratio test against full-detail model: $F=5.9$; $\mathrm{df}=324,247 ; \mathrm{p}<0.001$ ). The common slope-different intercepts version provided the best compromise between parameter number and model fit, and so was used as the basis of further model simplifications (Fig. 1).

The common slope-different intercepts model assumed that mortality had a density-dependent component in all age classes in both winter and summer. Even if this component was not statistically significant or was very weak, a parameter was still present in the model. Additionally, any density-dependence operating in old age classes may have less effect on overall population size simply because the numbers surviving to these age classes are low, and so density-dependence in younger age classes may be more important in controlling population size. The next stage of simplification, therefore, removed the density-dependent component of mortality, starting from the oldest age class and successively moving towards the youngest age class. Ten parameters were removed by each step (10 bed-specific intercepts and 1 estuary-wide slope replaced by 1 estuary-wide intercept).

The removal of density-dependence in 3rd-winter and older mussels had little effect on the amount of variation in the observed data explained by the model (F-ratio test of model assuming density-independent mortality in 3rd-winter and older mussels against fulldetail model; $F=0.2 ;$ df $=302,247$; ns) (Fig. 5a). The amount of variation explained by the model decreased when density-dependence was removed from 3rdsummer as well as older mussels (Fig. 5a). This version of the model did not differ significantly from the fulldetail model $(F=0.7$; df $=312,247$; ns), but overestimated the estuary-wide density of all age classes by an average of $26 \%$ (Fig. 5b). Model versions assuming density-independent mortality in 2nd-summer or 1stwinter mussels predicted mussel densities much higher than those observed, and differed significantly from the full-detail model ( $F$-ratio test of model assuming density-independent mortality in 2nd-summer and older mussels against full-detail model: $F=9.8$; $\mathrm{df}=$ $332,247 ; \mathrm{p}<0.001)$. In contrast, the model assuming density-dependence in 3rd-winter and older mussels accurately described the estuary-wide age distribution (Fig. 5b). We decided that this model provided the best compromise between parameter number (80) and predictive power, and used it is the basis for further simplification (Fig. 1). It predicted an estuary-wide mussel density of $636 \mathrm{~m}^{-2}$.

In the previous model, density-independent mortality from the 3rd-winter age class was age-class-spe- cific, and so a separate parameter was required for each age class. To simplify this we investigated whether mortality was related to age class by regressing mortality against age class (Fig. 6a):

$$
d_{i, k}=p_{k}+q_{k} i
$$

where $p_{k}$ and $q_{k}=$ season-specific regression coefficients. Mortality was significantly and positively

(a) Full-detail model

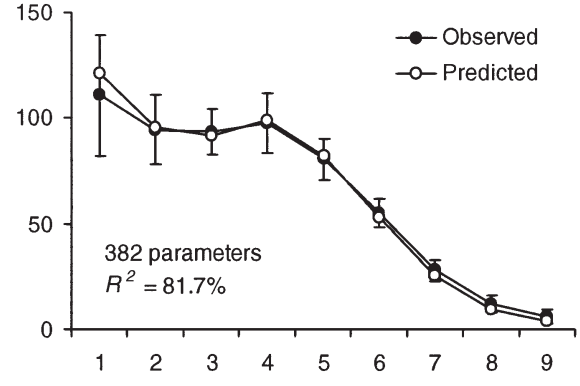

(b) Common slope, separate intercepts

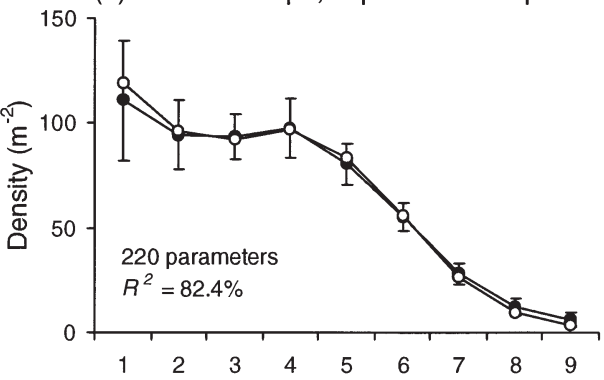

(c) Common slope and intercept

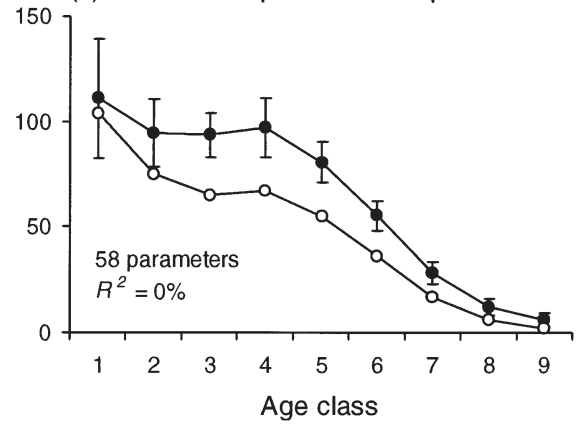

Fig. 4. Mytilus edulis. Effect of replacing bed-specific mortality parameters with estuary-wide parameters on the predicted estuary-wide age distribution in March: (a) full-detail model using bed-specific values for all parameters; (b) common slopes, separate intercepts model using estuary-wide densitydependent slope but bed-specific intercepts; (c) common slopes and intercepts model using estuary-wide densitydependent slopes and intercepts. Predictions are the mean estuary-wide age-class density during $50 \mathrm{yr}$ and observations are mean and between-year standard deviation of estuarywide age-class density during 1977 to 1983 
(a) Youngest age class with density-independence

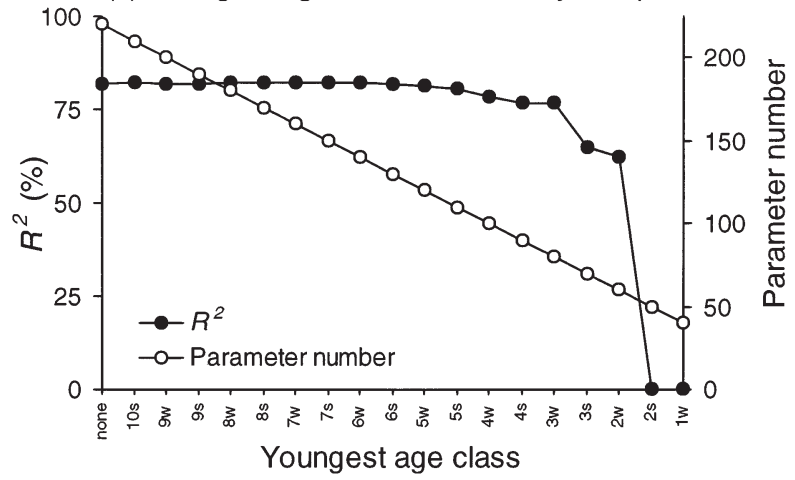

(b) Age distribution

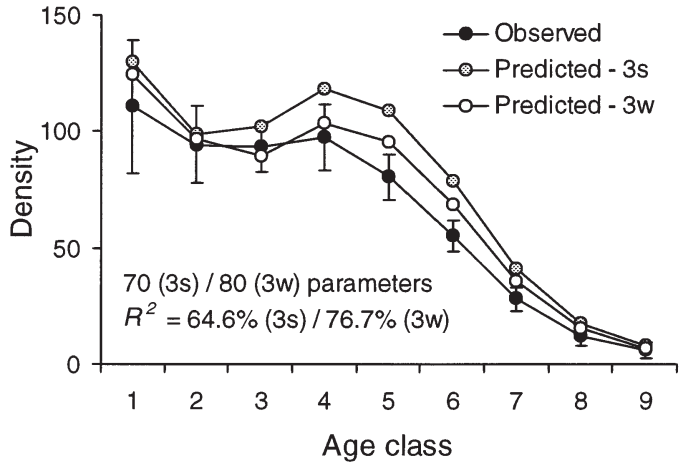

Fig. 5. Mytilus edulis. Effect of replacing bed-specific, density-dependent mortality parameters with estuary-wide, density-independent parameters. (a) Relationship between youngest age class in which mortality parameters are estuarywide and density-independent (in younger age classes they are density-dependent and bed-specific) and model's accuracy and parameter number; (b) predicted and observed estuary-wide age distribution in March, when predictions are based on density-independent, estuary-wide mortality in either 3rd-winter and older mussels (3w) or 3rd-summer and older mussels (3s) (see Fig. 4 legend for details of the predicted and observed values)

related to age class in summer $(k=2)$, but unrelated to age class in winter $(k=1)$ (Table 1$)$. We used the values of $p_{k}$ and $q_{k}$ to calculate age-class-specific mortality during both the summer and winter. We used the values for winter, even though they were insignificant, for consistency with the summer and because the relationship was significant and positive if the $k$-value for 9th-winter mussels (which was based on very low mussel densities and hence subject to a large error) was omitted. The model based on these relationships contained 70 parameters (14 age-class- and season-specific intercepts replaced by 4 season-specific regression coefficients) and had a closer fit to the observed data than the previous model (Fig. 1; F-ratio test against full-detail model: $F=0.2 ; \mathrm{df}=312,247 ; \mathrm{ns}$ ) (Fig. 6b). It predicted an estuary-wide mussel density of $623 \mathrm{~m}^{-2}$.

\section{(a) Age-dependent mortality}

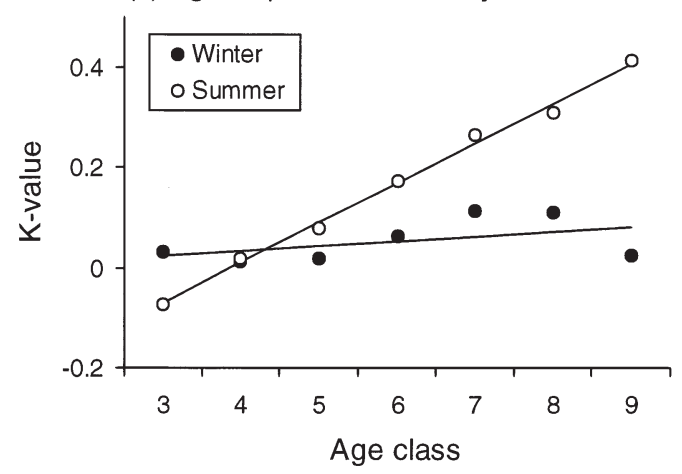

(b) Age distribution

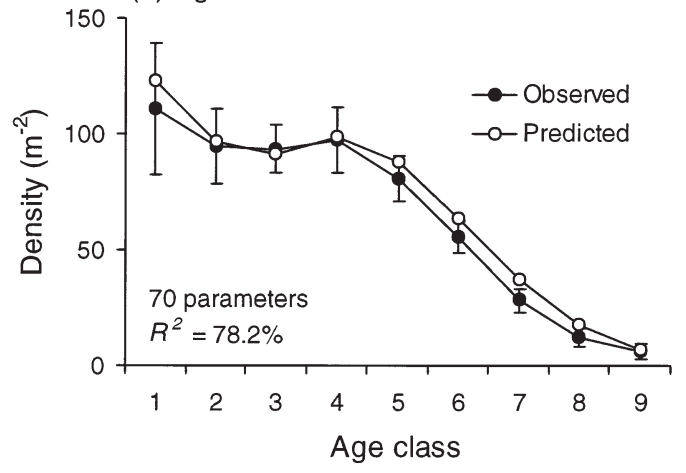

Fig. 6. Mytilus edulis. Effect of replacing age-specific, densityindependent mortality parameters in 3rd-winter and older mussels with values predicted from mussel age. (a) Relationship between age class and mortality rate. (b) Predicted and observed estuary-wide age distribution, when mortality rate is predicted from age (see Fig. 4 legend for details of the predicted and observed values)

The density-dependent relationships of 1st-winter to 3rd-summer mussels in the previous model assumed that intercepts differed among the different beds, and so had to be estimated on each bed. To simplify this, the relationship between the intercept on each bed and the physical characteristics of the bed were investigated. Following McGrorty \& Goss-Custard (1991), these characteristics were the distance between the bed and the mouth of the estuary, bed-substrate softness and the percentage of the tidal cycle during which the bed was exposed. Of these variables only bed exposure was consistently significantly related to the intercept, when expressed in a model as both a linear and quadratic term (Fig. 7a):

$$
C_{i, j, k}=r_{i, k}+s_{i, k} E_{j}+t_{i, k}\left(E_{j}\right)^{2}
$$

where $r_{i, k}, s_{i, k}$ and $t_{i, k}=$ age-class- and season-specific regression coefficients and $E_{j}=$ exposure of Bed $j$. All values of $s$ and $t$, except $s_{2,1}(\mathrm{p}<0.06)$ and $t_{2,1}(\mathrm{p}<0.11)$, 
Table 1. Parameter values estimated for Eqs. (9), (10), (11). See 'Results' for details of the equations. ns = not significant

\begin{tabular}{|c|c|c|c|c|c|}
\hline Eq. & Parameter & Estimate & SE & $\mathrm{n}$ & $\mathrm{p}$ \\
\hline $9(k=1)$ & $\begin{array}{r}p_{k} \\
q_{k}\end{array}$ & $\begin{array}{r}-0.0048 \\
0.0095\end{array}$ & $\begin{array}{l}0.0495 \\
0.0078\end{array}$ & 7 & $\begin{array}{l}\mathrm{ns} \\
\mathrm{ns}\end{array}$ \\
\hline $9(k=2)$ & $\begin{array}{l}p_{k} \\
q_{k}\end{array}$ & $\begin{array}{r}-0.3079 \\
0.0794\end{array}$ & $\begin{array}{l}0.0156 \\
0.0025\end{array}$ & 7 & $\begin{array}{l}<0.01 \\
<0.01\end{array}$ \\
\hline $10(i=1, k=1)$ & $\begin{array}{l}r_{i, k} \\
S_{i, k} \\
t_{i, k}\end{array}$ & $\begin{array}{c}1.159 \\
-0.1164 \\
0.00147\end{array}$ & $\begin{array}{l}0.407 \\
0.0259 \\
0.00041\end{array}$ & 10 & $\begin{array}{l}<0.05 \\
<0.01 \\
<0.01\end{array}$ \\
\hline $10(i=1, k=2)$ & $\begin{array}{l}r_{i, k} \\
S_{i, k} \\
t_{i, k}\end{array}$ & $\begin{array}{c}1.074 \\
-0.1524 \\
0.00202\end{array}$ & $\begin{array}{l}0.711 \\
0.0454 \\
0.00071\end{array}$ & 10 & $\begin{aligned} & n s \\
< & 0.05 \\
< & 0.05\end{aligned}$ \\
\hline $10(i=2, k=1)$ & $\begin{array}{l}r_{i, k} \\
S_{i, k} \\
t_{i, k}\end{array}$ & $\begin{array}{c}0.699 \\
-0.0887 \\
0.00113\end{array}$ & $\begin{array}{l}0.600 \\
0.0382 \\
0.00060\end{array}$ & 10 & $\begin{array}{l}\mathrm{ns} \\
\mathrm{ns} \\
\mathrm{ns}\end{array}$ \\
\hline $10(i=2, k=2)$ & $\begin{array}{l}r_{i, k} \\
S_{i, k} \\
t_{i, k}\end{array}$ & $\begin{array}{c}0.971 \\
-0.1527 \\
0.00198\end{array}$ & $\begin{array}{l}0.652 \\
0.0416 \\
0.00065\end{array}$ & 10 & $\begin{aligned} & \mathrm{ns} \\
< & 0.01 \\
< & 0.05\end{aligned}$ \\
\hline 11 & $\begin{array}{l}u \\
V\end{array}$ & $\begin{array}{l}8.813 \\
1.248\end{array}$ & $\begin{array}{l}2.853 \\
0.223\end{array}$ & 10 & $\begin{array}{l}<0.05 \\
<0.05\end{array}$ \\
\hline
\end{tabular}

were significantly different from zero (Table 1). These non-significant parameter estimates were still used because they had the same signs as the significant ones (negative $s$ and positive $t$ ) and a similar fitted relationship (Fig. 7a). These relationships were used to calculate the bed-specific intercepts in a simplified version of the model. This model contained only 42 parameters (40 age-class-, bed- and season-specific intercepts replaced by 12 age-class- and season-specific regression coefficients), but had a poorer fit to the data than the previous version $\left(\mathrm{R}^{2}=55.6 \%\right.$ compared with $78.2 \%$ ). However, it still accurately described the estuary-wide density-age structure (Fig. 7b) and did not differ significantly from the full-detail model $(F=$ $1.0 ; \mathrm{df}=340,247$; ns). It was therefore used as the basis for further simplification (Fig. 1). It predicted an estuary-wide mussel density of $580 \mathrm{~m}^{-2}$.

The last stage in model simplification was to reduce the number of parameters used to describe recruitment. In the previous models, the density of new recruits on each bed in September was related to the density of adults on the bed using a bed-specific regression equation. We attempted to find an estuarywide relationship which incorporated the bed-specific differences in recruitment as a function of their physical characteristics. Preliminary analysis showed that apart from adult density, the density of new recruits was most strongly related to the substrate softness of the bed. As spat on the Exe usually settle amongst adults, the relationship needed to predict no recruitment when adults were absent. Additionally, the density of recruits was non-linearly related to substrate softness. A model was developed with both of these attributes and accurately described the among-bed variation in recruitment (Fig. 8a,b):

$$
D_{1, j, 1}=\frac{u \sum_{i=2}^{10} D_{i, j, 1}}{\left(S_{j}\right)^{V}}
$$

where $u$ and $v=$ non-linear regression coefficients and $S_{j}=$ substrate softness of Bed $j$. Both $u$ and $v$ were significantly greater than zero (Table 1), indicating that recruitment was higher when more adults were present, but lower on softer beds. When incorporating this relationship, the model contained only 24 parameters (20 bed-specific slopes and intercepts, replaced by 2 regression coefficients), still described the estuarywide density-age structure with a reasonable degree of precision (Fig. 8c), and did not differ significantly from the full-detail model ( $F=0.7$; df $=358,247$; ns $)$. It predicted 568 mussels $\mathrm{m}^{-2}$ in March. This was the simplest version of the model (Fig. 1).

\section{Stability of simplest model}

Even though the simplest model described the mussel density-age structure almost as well as the fulldetail model, it would be less useful if it were less stable when the mussel population underwent large perturbations. To test this, we investigated how the predicted March estuary-wide mussel density was influenced by variation in the initial density of adults and the density of recruits per adult (Parameter $u$ of 
Eq. 11) settling each year. Variation in the initial density of adults from 100 times less to 100 times more than the standard value had no influence on predicted mussel density (Fig. 9a). This was due to strong density-dependent regulation in Age Classes 1 and 2 (the only age classes in which mortality was density-dependent); mortality was very low in small populations, and so they increased in size, whereas it was very high in larger populations, and so they decreased in size. In contrast, variation in the densities of recruits settling each year did influence predicted mussel density (Fig. 9b). When the density of recruits was lower than $30 \%$ of the standard value, the mussel population decreased in size because recruitment was insufficient to replace mortality. When the density of recruits was higher than the standard value, the predicted mussel density increased. However, the proportional increase in mussel density was much lower than the proportional increase in recruitment (e.g. a 100-fold increase

(a) Intercept (c)

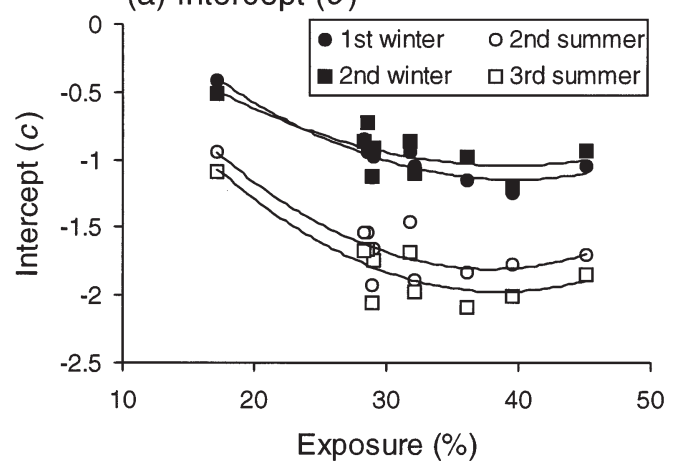

(b) Age distribution

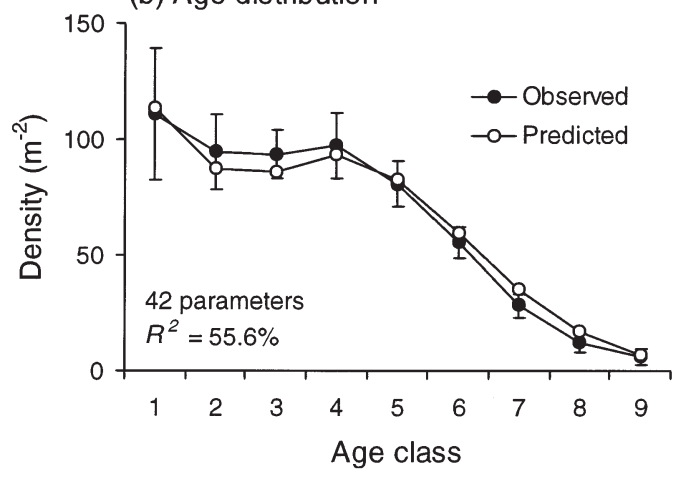

Fig. 7. Mytilus edulis. Effect of replacing bed-specific, density-dependent mortality intercepts (parameter $c$ ) for 1st winter to 3rd-summer mussels with values predicted from bed exposure. (a) Relationship between bed exposure and densitydependent mortality intercept. (b) Predicted and observed estuary-wide age distribution, when intercepts are predicted from bed exposure (see Fig. 4 legend for details of the predicted and observed values) in recruitment caused a 2-fold increase in mussel density) and the increase in mussel density was restricted to Age Classes 1 and 2. This was due to strong densitydependent regulation in Age Classes 1 and 2, which meant that their own densities varied by less than the variation in recruitment and that the densities of older mussels were unaffected by recruit density (Fig. 9b). In summary, even though there were far fewer density-

(a) Substrate softness

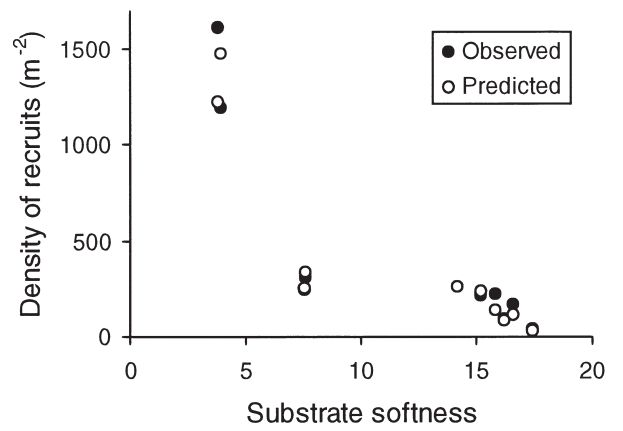

(b) Adult density

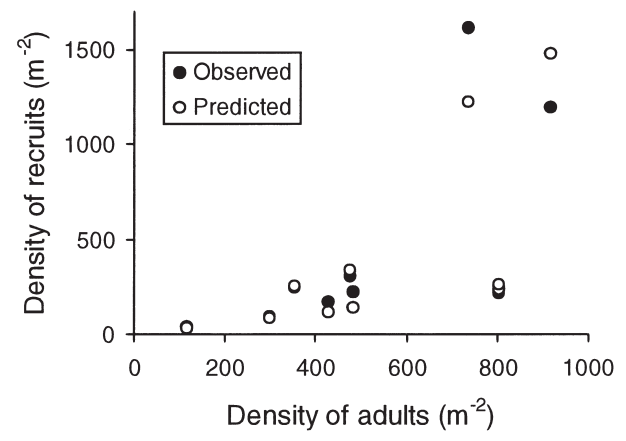

(c) Age distribution

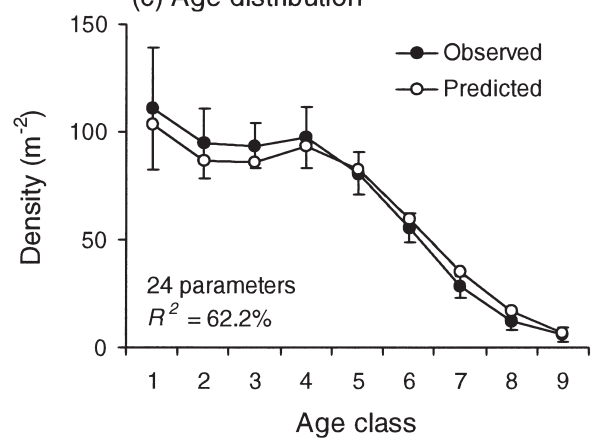

Fig. 8. Mytilus edulis. Effect of replacing bed-specific recruitment parameters with values predicted from substrate softness and adult density. (a) Relationship between bedsubstrate softness and recruit density; (b) relationship between adult density and recruit density; (c) predicted and observed estuary-wide age distribution, when recruitment is predicted from substrate softness and adult density (see Fig. 4 legend for details of the predicted and observed values) 
(a) Variation in initial adult density

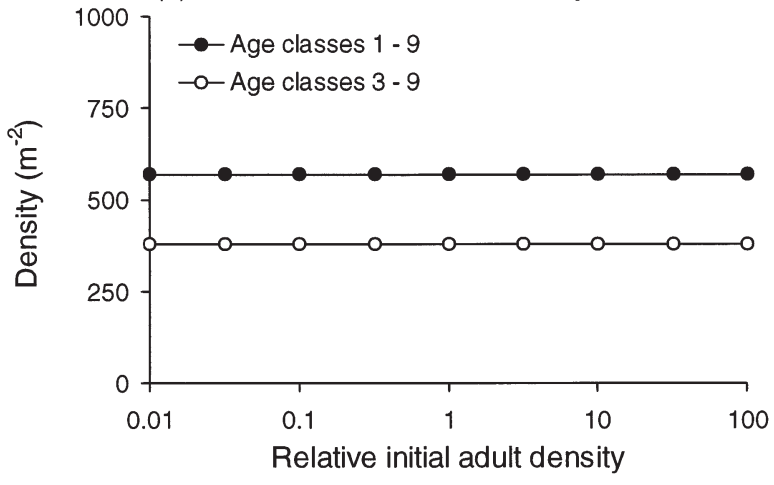

(b) Variation in recruit density

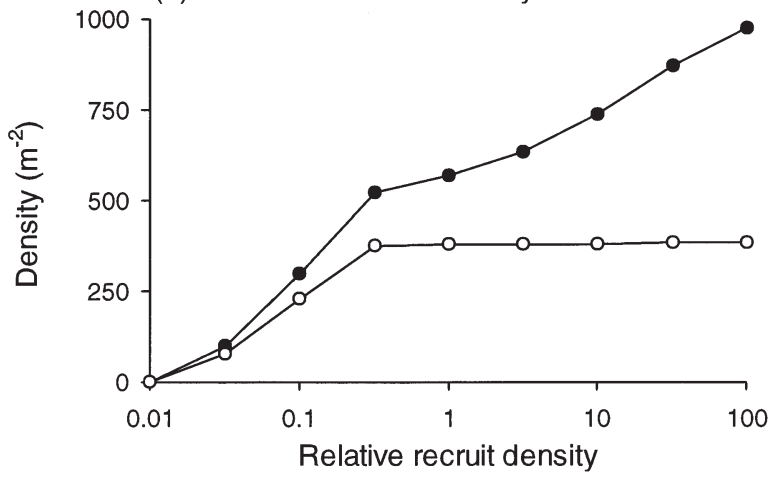

Fig. 9. Mytilus edulis. Stability of simplest version of model when (a) initial adult population or (b) density of recruits per adult vary from 100 times less than to 100 times greater than values observed in the Exe estuary. Predictions are estuarywide densities of all age classes combined (•) or Age Classes 3 to 9 (०)

dependent relationships in the simplest model than in the full-detail one, these were still sufficient to generate strong density-dependent regulation in the mussel population. The predicted size of the population was only changed, to any extent, when the density of recruits decreased substantially below that observed.

\section{Predictions of the simplest model}

The model predicts that the densities of mussels on the different mussel beds should change very little through time. Furthermore, no significant relationships were found between any of the model's parameters and climatic variables, and so variation in the weather (at least within the range observed between 1976 and 1983) will not influence the model's predictions. In order to test the model, the predicted density of adult mussels (2nd-summer and older) was compared with the density of adults recorded in mussel bed surveys in September 1992, 1995 and 1997. The comparison was restricted to adult mussels because these surveys did not allocate mussels to individual age classes. As predicted, the densities of adult mussels varied very little between 1976 and 1983 and between 1992 and 1997. The model predicted a stable estuarywide September mussel population of 524 adults $\mathrm{m}^{-2}$ and the observed estuary-wide density changed relatively little between 1976 and $1983\left(541 \mathrm{~m}^{-2}\right)$ and between 1992 and $1997\left(450 \mathrm{~m}^{-2}\right)$. The mussel populations on individual beds were also relatively stable (Fig. 10); linear regressions of observed adult density against year were non-significant ( $p>0.05$ ) on 8 beds, significant $(\mathrm{p}<0.05)$ and positive on Bed 20, and significant $(\mathrm{p}<0.05)$ and negative on Bed 26, indicating that there was no consistent change in mussel density with time. Because of this, the model's predictions were just as accurate between 1992 and 1997 as they were between 1976 and 1983 (Fig. 10), even though the model's parameter values were based on data collected only during 1976 and 1983.

\section{DISCUSSION}

The accuracy with which the model predicted the observed age structure of mussel Mytilus edulis densities and its stability were virtually unchanged as the number of parameters decreased from 382 to 24 . Although, the aggregated prediction of estuary-wide age structure was presented throughout most of the paper, this was in fact derived from 90 separate predictions of the density of 9 age classes on 10 beds. Additionally, predictions were made for both September and March and so, in total, the model generated 180 predictions each year. The number of parameters could have been reduced even further if predictions were only required for one time of year or a single bed.

The model accurately predicted the observed density-age structure between 1976 and 1983, but it could be argued that this arose simply because the model was compared against the data used to develop it. But in fact it was not necessarily the case that the model would produce accurate predictions. Predictions diverged widely from observations when the model became too simplified (e.g. when density-dependent mortality was assumed to be the same on all beds [Fig. 4c] or when mortality was assumed to be densityindependent in 3rd-summer and younger mussels [Fig. 5a]). Perhaps the main evidence that the model provides a realistic description of the real system comes from the accuracy of its predictions for the Exe mussel population in the 1990s. The model predicted a very stable mussel population, and as predicted, the density of adult mussels on the Exe varied little between 1976 and 1983 and between 1992 and 1997. 

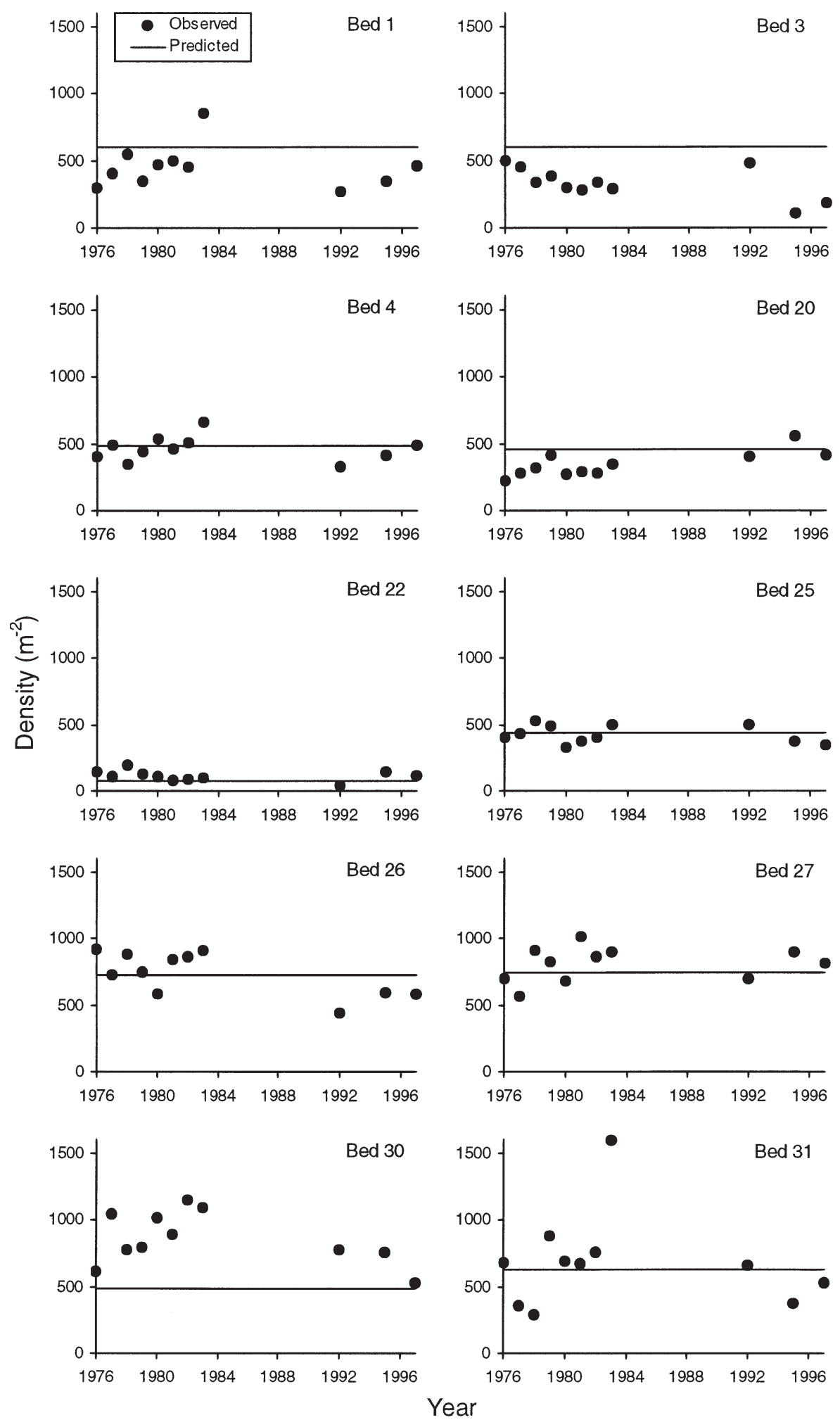

Fig. 10. Mytilus edulis. Predicted and observed densities of adult (2nd-summer and older) mussels between September 1976 and 1983 and between 1992 and 1997 
The model could be simplified to such an extent because of certain characteristics of the mussel population. In particular, (1) the population is highly regulated by strong density-dependent mortality in a few young age classes, (2) the among-bed variation in mortality and recruitment are strongly related to environmental gradients between the different beds, and (3) changes in mortality among age classes occur in a predictable way. This meant that density-dependence could be omitted in age classes older than 3rd-summer, because regulation had already occurred, and that multiple bed-specific and age-class-specific parameters could be replaced with the parameters of regression equations using environmental factors or mussel age as explanatory variables. The extent to which these results are relevant to other systems largely depends on whether other systems share these characteristics.

The Exe mussels are typical of many intertidal populations in sheltered estuaries and embayments. Patches or beds are long-lived and adult densities are stable over long periods (McGrorty et al. 1990, GossCustard et al. 1996), barring sporadic fishing or other disturbance or damage. The formation of new beds in these areas is probably a rare event. Only 1 new bed has formed in the last $25 \mathrm{yr}$ in the Exe (S.M. pers. obs.). In contrast, populations in exposed locations (e.g. Morecambe Bay) consist of short-lived patches or beds derived often from a single dense spatfall onto 'bare' ground (Dare 1973, 1976). If these dense patches of uniformly small mussels are not destroyed by swarms of starfish (Dare 1982), they grow rapidly, accumulating mud to a point of hydrodynamic instability in 1 to 3 yr, when the beds are destroyed by gales (Dare 1973, 1976, Nehls \& Thiel 1993). Even if mortality on the beds is density-dependent, the dynamics of these exposed populations is very different from that in the Exe, being dominated by the availability of spat to settle (so called 'supply-side' ecology: see Sale 1990 for review), space upon which to settle (Connell 1985, Roughgarden et al. 1985, Holm 1990, Sutherland 1990, Menge 1991, Caley et al. 1996) and the frequency of catastrophic events. The modelling approach used in this paper can probably be applied to mussel populations in sheltered estuaries and embayments, but probably not to the most exposed sites, at least not without being coupled to other models predicting the density of spatfalls and frequency of severe storms.

The life histories of some other bivalves such as Abra spp. (Gibbs 1984, Rainer 1985, Bachelet 1989) and Gemma gemma (Weinberg 1989) contrast with that of mussels in that they do not produce larvae which disperse in the plankton. However, these 'closed' systems can still be studied using age-structured models similar to ours (e.g. Weinberg 1989). The life histories of most other bivalves are similar to that of mussels, in that many small eggs are released into the plankton, where they grow for 2 to $3 \mathrm{wk}$ before settling among existing adult populations or elsewhere to form new beds. These are 'open' systems, because it is uncertain whether larvae return to the area of the parent stock or whether new recruits are derived from distant populations. It is generally assumed that the latter is most likely (Underwood \& Fairweather 1989), but Arnold et al. (1998) have shown that for the bay scallop Argopecten irradians there is little mixing between populations in adjacent bays, and separate populations occur where oceanographic features retain larvae locally. In general, life histories are similar across many species, but there are particular differences. For example, the relationship between recruit and adult density can be positive (e.g. mussels Mytilus edulis [McGrorty et al. 1993] and cockles Katelysia scalarina [Peterson \& Black 1993]) or negative (e.g. cockles Cerastoderma edule [Hancock 1973, Bachelet et al. 1992a,b], Mya arenaria [André \& Rosenberg 1991], and Chlamys islandica [Vahl 1982]), or recruits can settle in nursery areas apart from the adults and only later migrate into adult beds (e.g. Macoma balthica [Beukema 1973, Günther 1991, Armonies \& Hellwig-Armonies 1992]).

Whether age-structured models can be applied to other species depends on whether there are 1 or more strong density-dependent relationships in the early stages, so that large annual fluctuations in larval supply from the plankton are reduced substantially in the adult phase. In the yellow clam Mesodesma mactroides (Brazeiro \& Defeo 1999), there is a dome-shaped relationship between recruit and adult density, suggesting that adults in some way aid the settlement or survival of recruits below a threshold density, but at higher densities hinder them. Thereafter, mortality is density-dependent at all stages. In Macoma balthica, there is strong density-dependent mortality (Beukema 1982) in the upshore nursery areas in summer after settlement and before the winter migration downshore to adult beds. In cockles Cerastoderma edule in the Burry Inlet, Hancock (1973) described a strong negative relationship between adult stock and recruit density. In all species such as these, with strong density-dependent relationships at early stages, adult population size is determined mostly by post-settlement processes on the bed, and age-structured modelling is appropriate.

Age-structured modeling is less suitable for species in which there are no strong density-dependent relationships in the early stages. For example, other studies of cockles (Beukema 1982, Bannister 1998, 1999) have suggested that the stock-recruitment relationship, although negative, is weak and therefore population size is controlled more by the supply of spat than by processes operating on the bed. This leads to large annual fluctuations in adult populations driven by 
large fluctuations of spatfall in earlier years. In such cases, the modelling approach used in this paper cannot be applied without being coupled to a plankton model (Possingham \& Roughgarden 1990, Eckman 1996, Snodden \& Roberts 1997, Connolly \& Roughgarden 1999) which, as shown by studies in the Wash (Young et al. 1996, 1998), may need to include wind and current parameters.

One of the main reasons why our model could be so simplified was that the mortality of mussels was strongly related to environmental gradients within the estuary. Although shellfish growth has been shown to vary along environmental gradients (for example, Harvey \& Vincent 1991, Jensen 1992, Vincent et al. 1994, McGrorty 1997), variation in mortality has been measured less often (Sanchez-Salazar et al. 1987, McGrorty \& Goss-Custard 1991, 1993, 1995, Robles 1997). Species zonation patterns downshore or downestuary may be at least partially due to differential mortality, and such relationships with environmental variables might be found widely if looked for. In future studies, if relationships between mortality and environmental variables are known or strongly suspected, only a sample of patches along the gradient would need to be sampled and mortality on the remaining patches could then be predicted, thus saving time and resources.

Acknowledgements. We are grateful to 3 anonymous referees, whose comments much improved the manuscript.

\section{LITERATURE CITED}

André C, Rosenberg R (1991) Adult-larval interactions in the suspension-feeding bivalves Cerastoderma edule and Mya arenaria. Mar Ecol Prog Ser 71:227-234

Armonies W, Hellwig-Armonies M (1992) Passive settlement of Macoma balthica spat on tidal flats of the Wadden Sea and subsequent migration of juveniles. Neth J Sea Res 29: 371-378

Arnold WS, Marelli DC, Bray CP, Harrison MM (1998) Recruitment of bay scallops Argopecten irradians in Floridan Gulf of Mexico waters: scales of coherence. Mar Ecol Prog Ser 170:143-157

Bachelet G (1989) Recruitment in Abra tenuis (Montagu) (Bivalvia, Semelidae), a species with direct development and a protracted meiobenthic phase. In: Ryland JS, Tyler PA (eds) Reproduction, genetics and distributions of marine organisms. Proc 23rd Eur Mar Biol Symp. Olsen \& Olsen, Fredensborg, p 23-30

Bachelet G, Desprez M, Ducrotoy JP, Guillou J, Labourg PJ, Rybarczyk H, Sauriau OG, Elkaïm B, Glémarec M (1992a) Rôle de la compétition intraspécifique dans la régulation du recruitment chez la coque, Cerastoderma edule (L.) Ann Inst Océanogr 68:75-87

Bachelet G, Guillou J, Labourg PJ (1992b) Adult-survival and juvenile interactions in the suspension-feeding bivalve, Cerastoderma edule (L.): field observations and experiments. In: Colombo G, Ferrari, I, Ceccherelli IVU, Rossi R (eds) Marine eutrophication and population dynamics. Olsen \& Olsen, Fredensborg, p 175-182

Bannister C (1998) Analysing cockle and mussel stocks. Part 1. The wash. Shellfish News 6:25-29

Bannister C (1999) Analysing cockle stock. Part 2. Shellfish News 7:14-16

Bates DM, Watt D (1988) Nonlinear regression analysis and its applications. John Wiley \& Sons, New York

Beukema JJ (1973) Migration and secondary spatfall of Macoma balthica (L.) in the western part of the Wadden Sea. Neth J Sea Res 23:356-357

Beukema JJ (1982) Annual variations in reproductive success and biomass of the major macrozoobenthic species living in a tidal flat area of the Wadden Sea. Neth J Sea Res 16: $37-45$

Brazeiro A, Defeo O (1999) Effects of harvesting and density on the demography of sandy beach populations: the yellow clam Mesodesma mactroides of Uruguay. Mar Ecol Prog Ser 182:127-135

Caley MJ, Carr MH, Hixon MA, Hughes TP, Jones GP, Menge BA (1996) Recruitment and the local dynamics of open marine populations. Annu Rev Ecol Syst 27:477-500

Connell JH (1985) The consequences of variation in initial settlement vs post-settlement mortality in rocky intertidal communities. J Exp Mar Biol Ecol 93:11-45

Connolly SR, Roughgarden J (1999) Theory of marine communities, predation and recruitment-dependent interaction strength. Ecol Monogr 69:277-296

Dare PJ (1973) The stocks of young mussels in Morecambe Bay, Lancashire. Shellfish Inf Leaf Minist Agric Fish Food UK 28:1-14

Dare PJ (1976) Settlement, growth and production of the mussel, Mytilus edulis L., in Morecambe Bay, England. Fish Invest, Lond (Ser 2) 28(1):1-25

Dare PJ (1982) Notes on the swarming behaviour and population density of Asterias rubens L. (Echinodermata: Asteroidea) feeding on the mussel, Mytilus edulis L. J Cons Int Explor Mer 40:112-118

Eckman JE (1996) Closing the larval loop: linking larval ecology to the population dynamics of marine benthic invertebrates. J Exp Mar Biol Ecol 200:207-237

Gibbs PE (1984) The population cycle of the bivalve Abra tenuis and its mode of reproduction. J Mar Biol Assoc UK 64:791-800

Goss-Custard JD, McGrorty S, Durell SEA le V dit (1996) The effect of oystercatchers Haematopus ostralegus on shellfish populations. Ardea 84A:453-468

Günther CP (1991) Settlement of Macoma balthica on an intertidal sandflat in the Wadden Sea. Mar Ecol Prog Ser 76:73-79

Hancock DA (1973) The relationship between stock and recruitment in exploited invertebrates. Rapp P-V Cons Int Explor Mer 164:113-131

Harvey M, Vincent B (1991) Spatial variability of length-specific production in shell, somatic tissue and sexual products of Macoma balthica in the Lower St. Lawrence Estuary. I. Small and meso scale variability. Mar Ecol Prog Ser 75:55-66

Holm ER (1990) Effects of density-dependent mortality on the relationship between recruitment and larval settlement. Mar Ecol Prog Ser 60:141-146

Jensen KT (1992) Dynamics and growth of the cockle, Cerastoderma edule, on an intertidal mud-flat in the Danish Wadden Sea: effects of submersion time and density. Neth J Sea Res 28:335-345

McGrorty S (1997) Winter growth of mussels Mytilus edulis as a possible counter to food depletion by oystercatchers 
Haematopus ostralegus. Mar Ecol Prog Ser 153:153-165

McGrorty S, Goss-Custard JD (1991) Population dynamics of the mussel, Mytilus edulis: spatial variations in age-class densities of an intertidal estuarine population along environmental gradients. Mar Ecol Prog Ser 73:191-202

McGrorty S, Goss-Custard JD (1993) Population dynamics of the mussel Mytilus edulis along environmental gradients: spatial variations in density-dependent mortalities. J Anim Ecol 62:415-427

McGrorty S, Goss-Custard JD (1995) Population dynamics of Mytilus edulis along environmental gradients: densitydependent changes in adult mussel numbers. Mar Ecol Prog Ser 129:197-213

McGrorty S, Clarke RT, Reading CJ, Goss-Custard JD (1990) Population dynamics of the mussel Mytilus edulis: density changes and regulation of the population in the Exe estuary, Devon. Mar Ecol Prog Ser 67:157-169

McGrorty S, Goss-Custard JD, Clarke RT (1993) Mussel Mytilus edulis (Mytilacea) dynamics in relation to environmental gradients and intraspecific interactions. Neth J Aquat Ecol 27:163-171

Menge BA (1991) Relative importance of recruitment and other causes of variation in rocky intertidal community structure. J Exp Mar Biol Ecol 146:69-100

Nehls G, Thiel M (1993) Large-scale distribution patterns of the mussel Mytilus edulis in the Wadden Sea of SchleswigHolstein: do storms structure the ecosystem? Neth J Sea Res 31:181-187

Peterson CH, Black R (1993) Experimental tests of the advantages and disadvantages of high density for two coexisting cockles in a Southern Ocean lagoon. J Anim Ecol 62: 614-633

Possingham HP, Roughgarden J (1990) Spatial population dynamics of a marine organism with a complex life cycle. Ecology 71:973-985

Rainer SF (1985) Population dynamics and production of the bivalve Abra alba and implications for fisheries production. Mar Biol 85:253-262

Robles CD (1997) Changing recruitment in constant species assemblages: implications for predation theory in intertidal communities. Ecology 78:1400-1414

Editorial responsibility: Otto Kinne (Editor),

Oldendorf/Luhe, Germany
Roughgarden J, Iwasa Y, Baxter C (1985) Demographic theory for an open marine population with space-limited recruitment. Ecology 66:54-67

Sale PF (1990) Recruitment of marine species: is the bandwagon rolling in the right direction? Trends Ecol Evol 5: $25-27$

Sanchez-Salazar ME, Griffiths CL, Seed R (1987) The interactive roles of predation and tidal elevation in structuring populations of the edible cockle, Cerastoderma edule. Estuar Coast Shelf Sci 25:245-260

Snodden LM, Roberts D (1997) Reproductive patterns and tidal effects on spat settlement of Mytilus edulis populations in Dundrum bay, Northern Ireland. J Mar Biol Assoc UK 77:229-243

Stillman RA, Goss-Custard JD, West AD, Durell SEA le V dit, Caldow RWG, McGrorty S, Clarke RT (2000) Predicting mortality in novel environments: tests and sensitivity of a behaviour-based model. J Appl Ecol 37:564-588

Sutherland JP (1990) Recruitment regulates demographic variation in a tropical intertidal barnacle. Ecology 71: 955-972

Underwood AJ, Fairweather PG (1989) Supply-side ecology and benthic marine assemblages. Trends Ecol Evol 4: $16-20$

Vahl O (1982) Long-term variations in recruitment of the Iceland scallop, Chlamys islandica, from northern Norway. Neth J Sea Res 16:80-87

Vincent B, Joly D, Harvey M (1994) Spatial variation in growth of the bivalve Macoma balthica (L.) on a tidal flat: effects of environmental factors and intraspecific competition. J Exp Mar Biol Ecol 181:223-238

Weinberg JR (1989) Predicting population abundance and age structure: testing theory with field data. Mar Ecol Prog Ser 53:59-64

Young EF, Bigg GR, Grant A (1996) A statistical study of the environmental influences on bivalve recruitment in the Wash, England. Mar Ecol Prog Ser 143:121-129

Young EF, Bigg GR, Grant A, Walker P, Brown J (1998) A modelling study of environmental influences on bivalve settlement in The Wash, England. Mar Ecol Prog Ser 172: $197-214$

Submitted: November 19, 1999; Accepted: May 30, 2000

Proofs received from author(s): October 30, 2000 